\title{
The by-product effect on metal markets - New insights to the price behavior of minor metals
}

\author{
Patrick Afflerbach ${ }^{\mathrm{a}}$, Gilbert Fridgen ${ }^{\mathrm{b}}$, Robert Keller ${ }^{\mathrm{a}}$, Andreas W. Rathgeber ${ }^{\mathrm{c}, *}$, \\ Florian Strobel ${ }^{\mathrm{a}}$ \\ ${ }^{\text {a }}$ FIM Research Center, University of Augsburg, 86150 Augsburg, Germany \\ ${ }^{\mathrm{b}}$ FIM Research Center, University of Bayreuth, 95440 Bayreuth, Germany \\ ${ }^{c}$ Institute for Materials Resource Management, University of Augsburg, 86150 Augsburg, Germany
}

\section{A R T I C L E I N F O}

Article history:

Received 13 February 2014

Received in revised form

22 August 2014

Accepted 25 August 2014

Available online 8 October 2014

Keywords:

Metal prices

Joint production

By-product

Co-product

Empirical test

Minor metals

\begin{abstract}
A B S T R A C T
We will examine price dependencies between primary products and co-products from metal markets. First, we develop an optimization model to determine the profit-maximizing extraction behavior of mining companies. With this model, we analyze how the companies optimally react to exogenous demand shocks on the metal markets, and how the prices of metallic primary products and their coproducts are related to each other. This approach enables us to determine the basic conditions leading to price relationships. Second, we validate our theoretical findings on monthly metal prices from June 2009 to January 2013. We apply a linear regression model to analyze the price relationships of the primary products and their co-products and finally compare the results of our analysis to our model forecasts.
\end{abstract}

\section{Introduction}

Since 1980, the number of chemical elements in industrial use has more than quintupled (Theis, 2007). So-called minor and precious metals in particular are of increasing importance to the world's current industry (Lewis et al., 2011). The unique properties of these metals make them valuable for high tech applications (Hagelüken and Meskers, 2010). Minor metals are used in wind power, photovoltaic, carbon capture, sequestration, the oil sector, supercritical power plants, transports, energy efficient lighting or smart grids (Fizaine, 2013). Due to their rising importance, more and more studies such as European Commission (2010) or European Pathway to Zero Waste (2011) analyze the criticality of minor metals. One element that exemplarily underlines the increasing importance of these metals is selenium. Where it has been previously regarded as a waste product from the mining of copper ores, it is now an important source of revenue for the mining industry (Hagelüken and Meskers, 2010). Today, mining these selenium-containing copper ores is like killing two birds with one stone.

The term minor metals cannot be defined completely and precisely. It rather encompasses diverse metals which have several characterizing attributes. Originally, minor metals were those

\footnotetext{
*Corresponding authors: Tel +498215983040

E-mail address: andreas.rathgeber@mrm.uni-augsburg.de (A.W. Rathgeber)
}

metals not traded on major public exchanges apart from a few exceptions (Hagelüken and Meskers, 2010). Furthermore, minor metals are characterized by a relatively low production volume (Fizaine, 2013). Although palladium and platinum are traditionally classified as precious metals, we assign them to the group of minor metals for reasons of simplicity. This is because these two metals feature similar economic properties to minor metals. We do not include gold and silver since these metals have special economic attributes from their role as investment products. The term base metals includes aluminum, copper, lead, nickel, tin and zinc, metals which are widely used in industrial applications, have a relatively high production, and are traded on formal exchanges (Hagelüken and Meskers, 2010).

A special attribute of minor metals is that they are mostly produced jointly with base metals (Steinbach and Wellmer, 2010). There are only a few minor metals that are additionally extracted on their own, such as platinum (Hagelüken and Meskers, 2010). Within metallic joint production, there exist two possible set-ups of metal pairs. They are either defined as a combination of a main (or a primary) product and a by-product, or as co-products. Campbell (1985) defines a by-product as a secondary product from the extraction process of the primary product. The primary product determines the mining decision whereas the by-product has no effect on the profit-maximizing level of production. The byproduct just underlies a binary decision: either it is completely sold if it is profitable, or it is not sold if it is not profitable. As a 
Table 1

Definitions.

\begin{tabular}{|c|c|c|}
\hline & Minor metals & $\begin{array}{l}\text { Minor metals are mostly not traded on major public exchanges, they have relatively low production volumes and they are } \\
\text { predominantly extracted as by-products from base metal production (Hagelüken and Meskers, 2010). In addition, we assign the } \\
\text { (former) precious metals platinum and palladium to that metal group. }\end{array}$ \\
\hline 2 & Base metals & $\begin{array}{l}\text { Base metals are traded on major public exchanges, they have high production volumes, and they are widely used in industrial } \\
\text { applications (Hagelüken and Meskers, 2010). }\end{array}$ \\
\hline 3 & Co-product & $\begin{array}{l}\text { Co-products determine the extraction strategy along with one or more other co-products and they mutually influence their prices } \\
\text { (Campbell, 1985). }\end{array}$ \\
\hline 4 & Primary product & $\begin{array}{l}\text { Primary products determine the extraction strategy to a large extent and they influence the prices of the associated metals (Campbell, } \\
\text { 1985). }\end{array}$ \\
\hline 5 & $\begin{array}{l}\text { By-product (traditional } \\
\text { definition) }\end{array}$ & By-products do not determine the extraction strategy and they do not influence the price of the associated metals (Campbell, 1985). \\
\hline & $\begin{array}{l}\text { By-product (adapted } \\
\text { definition) }\end{array}$ & By products may influence the extraction strategy but they do not influence the price of the associated metal. \\
\hline
\end{tabular}

result, the price of the primary product influences the price of the by-product but not vice versa. Co-products in contrast directly influence the profit-maximizing production along with one or more other co-products and they mutually influence their prices (Campbell, 1985). As minor metals are typically regarded as byproducts of base metals, we also focus on the economic behavior within this set-up. However, we slightly adapt the definitions. Whereas primary products still determine the production decisions in the first line, we show in the following that the present market conditions for minor metal suggest that they should also be included in that decision. However, the one-sided price influence of the primary product on the by-products remains valid within our framework. Summing all up, we can state that our definition of by-products contains the traditional definition attribute of the one-sided price influence and the inclusion to the production decision, a characteristic typically reserved for coproducts. Our definition framework is summarized in Table 1.

Due to the rising importance of minor metals, the dynamics and the behavior of their prices are of major interest to producing companies. Existing models for optimal extraction strategies, like the models developed by Hotelling (1931), Campbell (1980), Crabbe (1982), and Lewis (1985), do not consider by-production, neither do traditional econometric models for commodity prices which typically focus on inflation, interest rate and industrial production (Awokuse and Yang, 2003) and exchange rate (Jain and Ghosh, 2013). The main reason for the lack of research within this topic may be the "lack of reliable price and production data" during the 20th century (Fizaine, 2013). This research gap is additionally underlined by Fizaine (2013) who states that economists should further analyze the mechanisms of minor metal markets to limit uncertainty. The preceding analysis leads to the following research question: Does the relationship between minor metals and base metals on the production site result in a price relationship between these metals? We will refer to this potential price relationship as the "by-product effect". To address this research gap, we extend current research results on metallic joint production by the formulation of a quantitative model. With our model, we are able to confirm the existing results and provide additional insights. In a next step, we empirically investigate these price dynamics.

\section{Literature review}

By taking a closer look at the economic literature, we find that joint production has been practiced for many years. The topic was initially addressed in economic theories by Adam Smith (1776) and Karl Marx (1867). These two theorists were followed by Merian (1932), Arrow and Debreu (1954) and Riebel (1955), who modeled external effects as by-products. In recent years, authors from several research domains developed different approaches to joint production, covering topics from oil production (Tamunaidu and Bhatia, 2007), chemistry and biology (Ayres, 1995; Blömer and Günther, 1998; Nalle et al., 2004; El-Diwani et al., 2012), the brewing industry (Scheiby, 2009) and general production theory (Sakai, 1974). However, these approaches can hardly be applied to determine optimal extraction strategies within metallic joint production because of two reasons: First, some approaches apply a variable proportion between the primary product and the byproduct (El-Diwani et al., 2012), and thereby contradict the constant proportion in metallic joint-production (Hagelüken and Meskers, 2010). Second, some authors focus on other aspects of production strategy, such as speeding up production (Blömer and Günther, 1998) or the minimization of unsuitable outcomes (Nalle et al., 2004).

In addition to the approaches inspired by general production theory, there exist models that include characteristics of metal markets. Campbell (1985) analyzes the metallic joint production using an equilibrium model and an empirical approach. Campbell (1985) bases his theoretical framework on an analysis of the shortrun demand and supply behavior of the entire mining industry and finally states that the prices of co-products have a negative relationship when the demand for only one metal shifts, or when the demands for both metals shift in opposite directions (where all other factors are constant). He furthermore reveals that coproduct price relationships are indeterminate when demand for the co-products move in the same direction. Campbell finally states that the price cycles of metals develop differently, (demand shifts in opposite direction) which leads to a diversification effect for multi-metal mining. This claim is supported by a sign test for the metal-price-movements of copper, molybdenum, silver, gold, lead, and zinc between 1950 and 1982. However, metal markets have changed since the study was conducted. Chen et al. (2010) analyze positive correlations between the London Metal Exchange Index and nearly every metal, which indicates that the price cycles of metals are not independent anymore. Therefore, this result cannot be directly transferred to the present markets for minor metals. However, the statements about the negative price relationship in demand shifts on one metal market and the indeterminate effects in the case of parallel demand shifts on both metal markets still remain valid.

Fizaine (2013) transfers the results of Campbell (1985) to the present markets of minor metals and empirically analyzes their validity. Concerning the price relationship between minor metals (gallium, indium, molybdenum, selenium, tellurium) and their base metals (aluminum, copper, zinc), he reproduces the results of Campbell (1985). He analyzes price data from 1950 to 2011 on a yearly basis provided by the United States Geological Survey (USGS) and confirms that the prices for minor metals behave independently from the prices of their base metals. However, the 
changed conditions on the metal markets during the last years (Chen et al. 2010) and the increased industrial use of minor metals since the 1990s (Theis, 2007) may not be visible in this analysis. Fizaine (2013) also examines the causality between the output of base metals and associated minor metals. He illustrates by a cointegration analysis that some of the productions "seem to vary at the same time" (molybdenum-copper and selenium-copper). Other metal pairs do not validate this linear link. In addition Fizaine (2013) "cannot exclude a more complex relationship" between productions and concludes that further research regarding the relationships between base metals and minor metals is required.

Kim and Heo (2012) illustrate empirically that Grangercausality is given between by-products used in thin-film PV-cells. They discover a price relationship between zinc and cadmium, zinc and germanium, and copper and selenium between 2004 and 2011. Pindyck (1982) sets up a mathematical model on the basis of Hotelling (1931) that investigates jointly produced metals but he does not examine price dependencies between these metals. Similar to the work of Campbell (1985), Naumov and Grinberg (2009) identify four possible trends of by-product prices by applying the general law of demand. Naumov and Grinberg (2009) reveal that the state of the raw material base and the possibilities of an increase in production are largely determined by the developmental phase of the basic metal. If the mining of one metal decreases and the demand for the associated metal increases then the price of the associated metal rises. In contrast, if the mining of one metal increases and the demand for the associated metal declines, then the price of the associated metal decreases. If production and demand move in the same direction, the prediction of the metal prices is not possible.

In the following, we develop a theoretical model that rests upon Campbell (1985), Naumov and Grinberg (2009) and Fizaine (2013). These authors apply the general law of demand, and come to the conclusion that the relationship between the prices of primary products and the prices of by-products can either be negative or indeterminate. We set up an optimization model, which reproduces their results and allows us to analyze in greater detail under which conditions the relationship is negative or indeterminate. Furthermore, we empirically analyze whether these findings can be adopted for today's metal markets. We extend existing empirical approaches by using a wider data pool of minor metals with a higher data frequency. In return, we have to accept in accordance with Kim and Heo (2012) shorter time series than Campbell (1985) and Fizaine (2013). The application of our data pool enables us to capture the characteristics of the present metal markets and to derive more reliable results, given the structural demand changes for minor metals. Moreover, we refer to our theoretical results to adjust the existing empirical methodologies. Through this process we can provide further insight into the price dynamics of minor metals.

\section{Theoretical foundation}

\section{Basic idea and general market setting}

The economic decisions of mining companies regarding their extraction strategies for minor metals have two important features. First, these companies must jointly optimize the primary product market (the market of the base metal) and the by-product market (the market of the minor metal). Second, they must take into account that the production of the primary product is delivering the capacity for the production of the by-product. In other words, the extraction decisions are clearly influenced by the constant proportion between the primary products and their by- products. In turn, extraction strategies directly influence market prices. Therefore the economic calculus of the mining industry transforms the geological relationship between the primary product and the by-product into a monetary relationship.

Extraction decisions are very complex and therefore require some assumptions in order to derive a descriptive model. We assume that mining companies act rationally in the sense of profitmaximization. The discussion of the validity of this assumption is ongoing in economic history (Gordon, 1948), and is the basis for many models in the field of resource management (e.g. Averch and Johnson, 1962). However, economists agree that, in case of certainty, it is unproblematic to assume that companies act in a way that maximizes profit (Alchian, 1950). This theory leads us to our second assumption: determinism. We apply a ceteris paribus approach, similar to Campbell (1985), in order to analyze the price dependencies of primary products and their by-products. Determinism is a typical characteristic of this approach from a general equilibrium theory (Bierens and Swanson, 2000).

In the following section, we introduce the general market setting upon which our model is based. When analyzing the structures of metal markets, published by Lewis et al. (2011) or Ayres et al. (2002), it seems that base metals (the primary products in our model) can be assumed to be traded in unconcentrated markets, whereas minor metals (by-products) are usually traded in concentrated markets (Fizaine 2013). Based on our findings, we model the market for the primary product as a market with complete competition and the by-product market as an oligopoly in a microeconomic sense. The analysis of the strategic behavior of market players in an oligopoly typically requires the application of game-theoretic approaches. The special case of an oligopoly which is characterized by identical conditions for every market player constitutes an exception (see Cournot competition (Cournot, 1927)). For our purpose, we can use this special case of an oligopoly, because it is as any oligopolistic market characterized by the price influence of the market players. In addition, the application of this special oligopoly avoids the inflation of our model by game-theoretic considerations. In line with "Occam's Razor", we decided to keep our model simple at this point and to concentrate on the essential characteristics of the minor metal markets.

\section{Separate optimization of the metal markets}

In markets with complete competition, market players cannot influence prices with their behavior. Consequently, the price on the primary product market $p_{P} \in \mathbb{R}^{+}$is a given parameter. Concerning the cost structure of the primary product, we apply the same approach of increasing marginal costs as does Campbell (1985). This means that the production costs $c_{P}\left(y_{P}\right) \in \mathbb{R}_{0}^{+}$are a monotonically increasing convex function of the production of the primary product $y_{P} \in \mathbb{R}_{0}^{+}$. One method used to model increasing marginal production costs is the application of a power function:

$c_{P}\left(y_{P}\right)=k y_{P}^{e} \quad$ with $e>1$ and $k>0$

The profit function for the primary product market $Q_{p}$ can be derived as the difference between the revenue $p_{P} y_{P}$ and the corresponding costs $c_{P}\left(y_{P}\right)$ :

$Q_{P}=p_{P} y_{P}-k y_{P}^{e} \quad$ with $e>1$ and $k>0, \forall y_{P} \in \mathbb{R}_{0}^{+}$

For the sake of simplicity and without losing generality we set $e=2$ and $k=1$ :

$Q_{P}=p_{P} y_{P}-y_{P}^{2}$

According to microeconomic theory, the profit-optimum of markets with perfect competition is characterized by the interception of the market price and the marginal costs $\frac{\partial c_{P}\left(y_{P}\right)}{\partial y_{P}}$. 
Therefore, the separate optimum of the primary market equals $\hat{y}_{P}=\frac{p_{P}}{2}$.

To model demand on the by-product market or the relationship between the by-product price $p_{B} \in \mathbb{R}_{0}^{+}$and the production of the by-product production $y_{B}^{\text {market }} \in \mathbb{R}_{0}^{+}$we apply a linear price demand curve with an axis intercept $A_{B} \in \mathbb{R}^{+}$and a slope $b_{B}^{\text {market }} \in \mathbb{R}^{+}$:

$p_{B}=A_{B}-b_{B}^{\text {market }} y_{B}^{\text {market }}$

The production of the by-product for the entire market ( $n$ market players) can be divided up into the productions of the single market players $y_{B}^{i} \in \mathbb{R}_{0}^{+}$with a maximal production capacity as upper bound $Y_{B}^{i} \in \mathbb{R}_{0}^{+}$:

$p_{B}=A_{B}-b_{B}^{\text {market }} y_{B}^{\text {market }}$ with $y_{B}^{i} \in\left[0, Y_{B}^{i}\right], y_{B}^{\text {market }}=\sum_{i=1}^{n} y_{B}^{i}$

In the special case of an oligopoly with identical conditions, every market player produces the same quantity of the by-product $y_{B} \in \mathbb{R}^{+}$in the equilibrium (Cournot, 1927) Therefore, we can simplify Eq. (5) to the following form:

$p_{B}=A_{B}-b_{B}^{\text {market }} n y_{B}=A_{B}-b_{B} y_{B}$ with $b_{B}^{\text {market }} n:=b_{B}$,

$y_{B} \in\left[0, Y_{B}\right]$

Concerning the cost function, we use constant marginal costs $d \in \mathbb{R}_{0}^{+}$for the by-product. The profit $Q_{B}$ equals again the difference between the revenue $\left(A_{B}-b_{B} y_{B}\right) y_{B}$ and the costs $\mathrm{y}_{B} d$ :

$Q_{B}=\left(A_{B}-b_{B} y_{B}\right) y_{B}-y_{B} d$ with $d<A_{B}$

Please note that $d<A_{B}$ holds true, because otherwise the companies do not produce any unit of the by-product. According to microeconomic theory, the profit-optimum for one market payer within such an oligopoly is characterized by the interception of the marginal revenue and the marginal costs $d$ Therefore, the separate optimum of the by-product market equals $\hat{y}_{B}=\frac{A_{B}-d}{2 b_{B}}$ and it is shown in Fig. 1.

\section{Optimization model}

In order to obtain the profit-maximal solution, both markets have to be optimized jointly. Therefore, the objective function $Q$ equals the sum of both profit functions:

$Q=Q_{P}+Q_{B}=p_{P} y_{P}-y_{P}^{2}+\left(A_{B}-b_{B} y_{B}-d\right) y_{B}$

The separate optima for productions of the by-product $\hat{y}_{B}$ and the primary product $\hat{y}_{P}$ optimize Eq. (8), but the separate optima

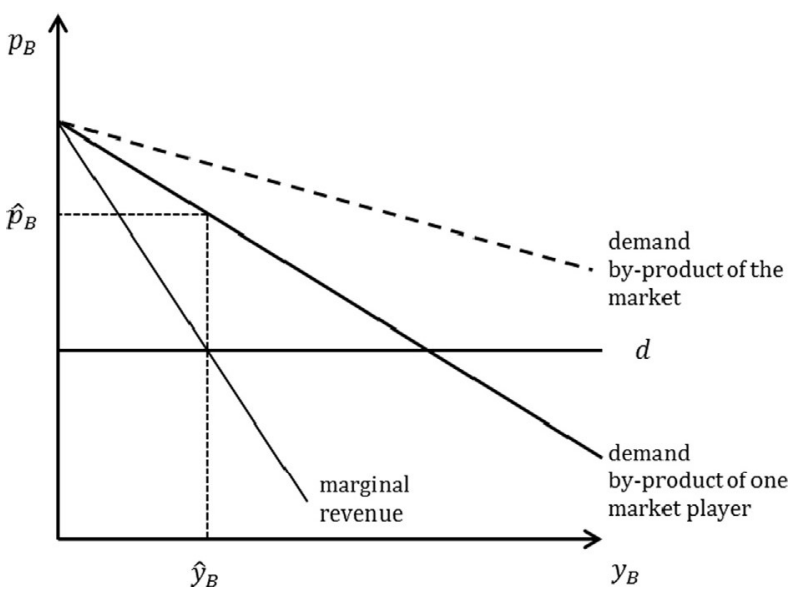

Fig. 1. Profit maximization in an oligopoly with identical conditions for the market players. usually do not fit the constant proportion of the underlying ore. In reality, this proportion can vary within a certain range. However we assume a constant relation $a \in \mathbb{R}^{+}$of the by-product relative to its primary product for reasons of simplicity. In addition, we have to consider that some by-products can be refined without mining the primary product. The exclusive production of the by-product $\Omega \in \mathbb{R}_{0}^{+}$sums up the volume of the by-product, which originates from own mines such as cobalt (USGS, 2013) or platinum (Lewis et al., 2011), from the recycling of by-product-containing waste deposits e.g. indium (USGS, 2013), and from the recycling of consumption goods. As a result, the maximal production capacity for the production of the by-product $Y_{B}$ equals:

$Y_{B}=y_{P} a+\Omega$

Now we can set up the optimization model for mining companies:

$\max \quad Q=p_{P} y_{P}-y_{P}^{2}+\left(A_{B}-b_{B} y_{B}-d\right) y_{B}$

s.t.

(I) $y_{B} \geq 0 \quad ; y_{P} \geq 0 \quad$ (Non - negativity)

(II) $y_{P} a+\Omega \geq y_{B} \quad$ (Capacity by - product)

Constraints (I) and (II) assure that the companies set their optimal production volumes within their domains and introduce the geological relationship between the metals into the model. When analyzing the optimization problem, we can determine two conditions for the optimal production of the by-product $y_{B}^{*}$. First, an increasing production is profitable until the separate optimum of the by-product market $\hat{y}_{B}$ is reached. In other words, this threshold constitutes an upper boundary for the optimal production of the byproduct. Second, according to constraint (II) (Eq. 12), the production of the by-product is restricted by the production of the primary product. Therefore, the production of the primary product sets a further upper bound for optimal production of the by-product. For the solution of the optimization problem, a case differentiation concerning these upper bounds becomes necessary.

Case 1. If $\hat{y}_{B}<Y_{B}$ holds true, the separate optimum can be achieved and constraint (II) is not binding. Consequently, the companies extract the separate optimum for the production of the by-product $\hat{y}_{B}$. As a result, the two markets can be optimized independently of one another and the price of the by-product becomes independent from the price of the primary product, and there is no by-product effect (Fig. 2).

Case 2. If $\hat{y}_{B} \geq Y_{B}$ holds true, constraint (II) is binding and the separate optimum cannot be achieved. Thus, the companies will extract the maximal production capacity of the by-product $Y_{B}=y_{P} a+\Omega$. Clearly, the companies cannot sell more units of the by-product than the maximal production capacity $Y_{B}$.

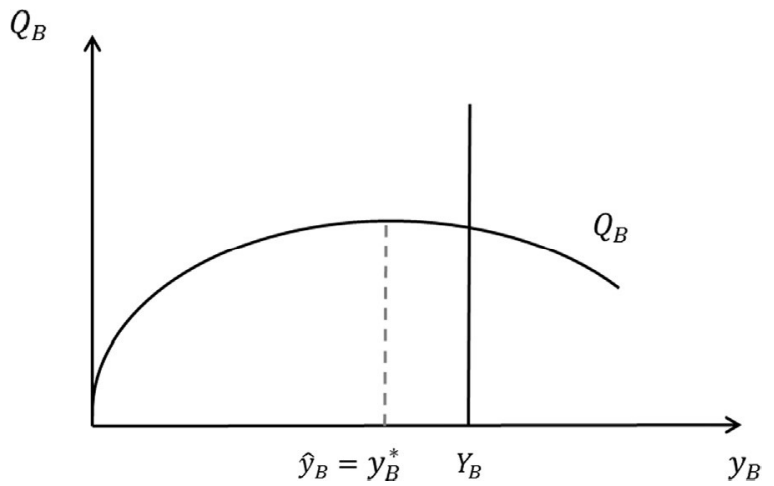

Fig. 2. Case 1: Separate optimal production. 


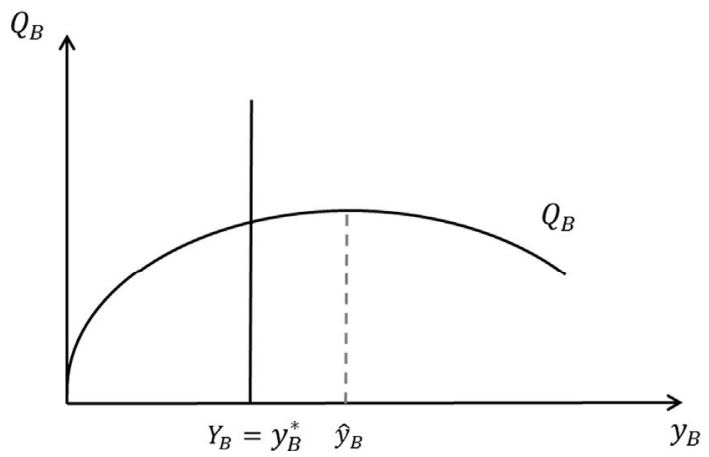

Fig. 3. Case 2: Maximal production capacity.

Moreover, the companies do not sell less because the separate profit function $Q_{B}$ is concave, indicating that the companies sets $y_{B}$ as close as possible to $\hat{y}_{B}$. The closest possible amount $y_{B}$ is exactly equal to the maximal production capacity $Y_{B}$. In this case a change in the primary product production results in a change of the byproduct production, and the basic conditions for the existence of the by-product effect are fulfilled (Fig. 3).

\section{By-product effect}

In the following, we assume Case 2. In this case, a by-product effect may exist. Consequently, we can set the production of the by-product $y_{B}$ equal to the maximal production capacity, and the optimization problem then simplifies to an optimization with only one variable:

$\max \quad Q^{\prime}=p_{P} y_{P}-y_{P}^{2}+\left(A_{B}-b_{B}\left(y_{P} a+\Omega\right)-d\right)\left(y_{P} a+\Omega\right)$

s.t.

$\left(I^{\prime}\right) y_{P} \geq 0 \quad$ (Non - negativity)

The new optimization problem solves a trade-off concerning production of the primary product. If the companies enlarge their production of the primary product, the profit margin on the primary product market decreases as a result of an increase in marginal costs. If the extension of the production reaches a certain threshold, the mining companies will even begin to incur losses. However, the companies can increase the production of the byproduct to take additional profits on the by-product market and to compensate for the losses from the primary product market. For the solution of this trade-off, we derive the objective function (10') with respect to the production of the primary product $y_{P}$ to determine the first order condition:

$\frac{\partial Q^{\prime}}{\partial y_{P}}=p_{P}-2 y_{P}+a A_{B}-2 a^{2} b_{B} y_{P}-d a-2 b_{B} a \Omega=0$

By resolving Eq. (13), we identify a candidate for the optimal production of the primary product $y_{P}^{*}$ :

$y_{P}^{*}=\frac{p_{P}+a A_{B}-a d-2 a b_{B} \Omega}{2+2 a^{2} b_{B}}$

Now we can insert $y_{P}^{*}$ in Eq. (9) to derive a candidate for the optimal production of the by-product $y_{B}^{*}$ :

$y_{B}^{*}=y_{P}^{*} a+\Omega=\frac{a p_{P}+a^{2} A_{B}-a^{2} d-2 a^{2} b_{B} \Omega}{2+2 a^{2} b_{B}}+\Omega$

If we insert $y_{B}^{*}$ into the demand function of the by-product market, we can obtain the resulting by-product price $p_{B}^{*}$ as a function of the primary product price. This equation represents the by-product effect:

$p_{B}^{*}=A_{B}-b_{B} y_{B}^{*}=A_{B}-b_{B} \frac{a p_{P}+a^{2} A_{B}-a^{2} d-2 a^{2} b_{B} \Omega}{\left(2+2 a^{2} b_{B}\right)}-b_{B} \Omega$

In order for solution candidates to be optimal, they must fulfill two additional requirements. They must lie within their domain, which is ensured by the case distinction and the second-order condition must be fulfilled, which is revealed by Eq. (17):

$\frac{\partial^{2} Q^{\prime}}{\partial y_{P}^{2}}=-2-2 a^{2} b_{B}<0$ as $b_{B}>0$

With $b_{B}>0$ representing the typically negative price demand relationships, inequality (17) holds true. Now we can further investigate Eq. (16) to provide a more detailed analysis of the by-product effect and its underlying conditions.

\section{Demand shock}

A demand shock is generally defined as a shift of the demand curve on the primary product market. A positive demand shock is an upwards shift of the demand function. As a result of this shift, both price and production increase in the primary product market. A negative demand shock is a downwards shift of the demand function, where both price and production decrease in the primary product market. Therefore, we model shifting demand functions by changes of the price on the primary market $p_{P}$, assuming ceteris paribus.

Hypothesis 1. A demand shock leads to a negative relationship between the primary product price and the by-product price.

To prove the negative relationship between the price of the primary product and the price of the by-product in a demand shock, we show that the derivative of Eq. (16) with respect to $p_{P}$ is strictly negative:

$\frac{\partial p_{B}}{\partial p_{P}}=-\frac{a b_{B}}{2+2 a^{2} b_{B}}<0$ as $a b_{B}>0$

In order to illustrate our result, we describe how the model variables change in a positive demand shock (Fig. 4). The demand for the primary product rises from $D_{P, 1}$ to $D_{P, 2}$, whereas the demand for the by-product stays at the same level. Consequently, the price of the primary product rises from $p_{P, 1}$ to $p_{P, 2}$. As a result, the companies can increase the production on the primary market by covering the resulting increases of the marginal costs by the rising prices. In other words, the companies can increase their profits by increasing the mined amount of ore $\left(y_{P, 1} \rightarrow y_{P, 2}\right)$. Increasing production furthermore allows the companies to produce more units of the by-product $\left(y_{B, 1} \rightarrow y_{B, 2}\right)$. The companies' profits further enlarge because the new production of the by-product is closer to the separate optimum than the prior production. However, the companies must offer the by-product at a lower price to sell the additional production $\left(p_{B, 1} \rightarrow p_{B, 2}\right)$. The relationship of the two prices is negative. The argumentation remains the same for negative demand shocks.

\section{Equal price drivers}

In the following section, we allow parallel changes of both demand functions. This set-up is interesting, because Campbell (1985), Naumov and Grinberg (2009) also described parallel changes and in addition, it seems to be a common market condition (Chen et al., 2010). We will refer to this set-up as equal price drivers.

Hypothesis 2. The price relationship is indeterminate if the demand functions shift in the same direction. 

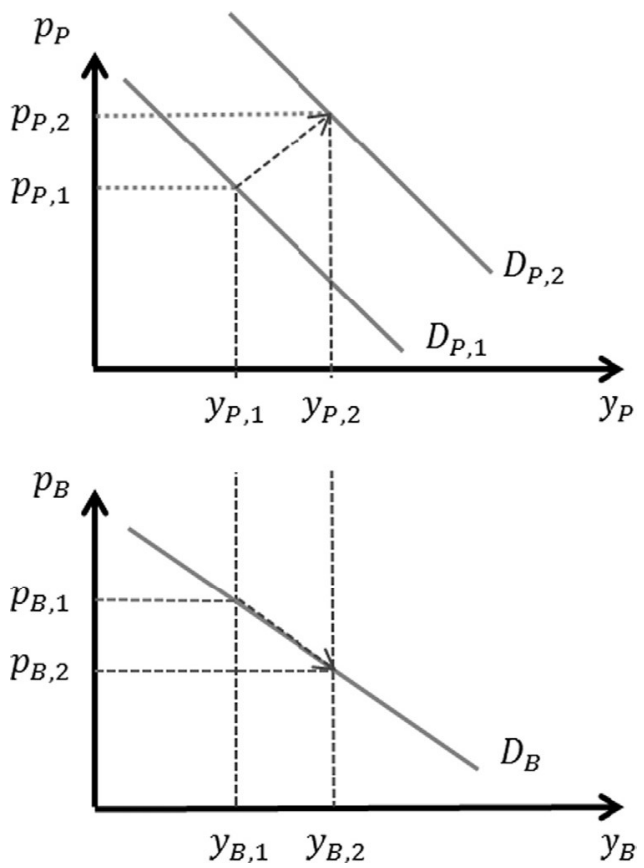

Fig. 4. Positive demand shock.

In addition to a changing price of the primary product $\Delta p_{P}$ as a result of the demand shock on this market, we model a shift of the by-product demand by a changing axis intercept $\Delta A_{B}$. To prove Hypothesis 2 within our theoretical framework, we must determine the overall effect $\Delta p_{B}$, which is the sum of two partial derivatives:

$\Delta p_{B}=\frac{\partial p_{B}}{\partial p_{P}} \Delta p_{P}+\frac{\partial p_{B}}{\partial A_{B}} \Delta A_{B}=-\frac{b_{B} a}{2+2 a^{2} b_{B}} \Delta p_{P}+\left(1-\frac{b_{B} a^{2}}{2+2 a^{2} b_{B}}\right) \Delta A_{B}$

These equations demonstrate that the sign of $\Delta p_{B}$ is indeterminate and depends on the absolute changes of the parameters $\Delta p_{P}$ and $\Delta A_{B}$. On the one hand, a positive shift of by-product demand enables the mining companies to impose higher prices on the market. On the other hand, there is a negative price influence from the positive demand shock on the primary product market. The negative price effect of increasing sales on the by-product market is settled with the positive price effect of the increasing demand. Without knowing the absolute values of the changes, it is impossible to decide which effect overrides the other one. This result is in line with the findings of Campbell (1985), and of Naumov and Grinberg (2009).

\section{Decoupling effect}

Decoupling of prices describes situations where the price relationship vanishes. These situations are characterized within Case 1 of our case distinction. Therefore, decoupling occurs when the following inequality holds true:

$\frac{A_{B}-d}{2 b_{B}}=\hat{y}_{B}<Y_{B}=y_{P} a+\Omega$

If we analyze inequality from the above Eq. (20), we can derive a couple of conditions for the decoupling effect. On markets with a small demand $\left(A_{B}\right.$ low) and a high cost structure ( $d$ high), the separate production optimum $\hat{y}_{B}$ is rather small. Technically spoken, the left-hand side of the inequality becomes small, and the prices of the by-products tend to be independent of the prices of the primary products (decoupling). In line with Fizaine (2013), another source of decoupling can be a large production of the primary product $y_{p}$. A larger production of the primary product results in a large amount of raw material for the production of the by-product production and small changes in production of the primary product do not affect the price of the by-product. Technically spoken, the right-hand side of the inequality becomes large and the prices of the by-products tend to be independent of the primary product (decoupling). Larger exclusive productions $\Omega$ have the same effects.

This analysis illustrates that our model is especially applicable to minor metals. Both the rising importance of minor metals in today's industry ( $A_{B}$ increasing) and the technical progress in the extraction process ( $d$ decreasing) lead to price dependencies (no decoupling). This line of argument is supported by studies such as Bublies et al. (2009) that identify a limited availability of these metals.

\section{Summary of the model-theoretic results}

In our optimization model, we take up the previous results on metallic joint production derived from the general law of demand and reproduce them analytically. The contribution of this approach is two-fold. On a meta-level, the analytical representation of the by-product effect enables a more detailed analysis of the different underlying influence factors and their interdependencies. We derive that the fundamental market conditions in general, the relationship between the capacity, and the economic boundary in particular determine the existence of a negative price relationship. Moreover, we can conclude that the market conditions for minor metals especially favor the existence of such price relationships. On a more specific level, we can adjust the existing research results from metallic joint production to the current situation of minor metals. We can formulate that price relationships between minor metals and base metals probably exist, though they do not occur in pure form as the dynamics of these relationships have two opposing components. The negative price relationship from the by-product effect and the positive price relationship from a global metal trend co-exist in today's markets. This means that the negative price relationship from the joint production has to be translated into a negative relationship between deviations from the global market trend. If the primary product outperforms the global market trend, the prices of the associated by-products realize in a level below the market trend. If the primary product underperforms the global market trend, the prices for the associated minor metals realize in a level above the market trend. In the following section, we empirically analyze the existence of the adjusted price relationships on the present metal markets.

\section{Empirical test of the by-product effect}

The optimization model suggests that a demand shock leads to a negative price relationship between the primary product and the by-product (Hypothesis 1) after the elimination of equal price drivers. In this section, we empirically validate this key finding for minor metals and base metals. First, we identify potential metal pairs and describe our data basis. Finally, we present our empirical methodology and interpret our results.

\section{Data base}

The empirical validation of our theoretical results is based on monthly metal log returns between June 15th 2009 and January 14th 2013. Given the increased industrial use of minor metals, the application of a wider time period is not reasonable for our purposes, because there is no reliable price data for many minor metals dating back more than five years. The data originates from 
the Thomson Reuters Data Stream. The base metal prices are extracted from the London Metal Exchange. With regard to the investigated minor metals, only the prices of Cobalt and Molybdenum are available at the London Metal Exchange. The other prices originate from Asia Metals. The basis for the identification of the relevant metal pairs is the work of Hagelüken and Meskers (2010). We extend their studies with the research results from Lewis et al. (2011), Ayres et al. (2002) and with data from the US Geological Survey (USGS, 2013). Our data base contains every minor metal except for arsenic, cadmium and ruthenium but including platinum and palladium. Arsenic, cadmium and ruthenium are excluded as their prices remain constant for more than $50 \%$ of the months during the analysis period. Yet, we are still able to establish a broader data pool than previous studies. Fig. 5 illustrates our data base.

\section{Methodology}

In contrast to the existing empirical analyses of the by-product effect, we first detrend the monthly log returns to eliminate the general market trend from our time series that may overlap the by-product effect as described in Theoretical foundation section. After this standardization of the log returns, the by-product effect should not be indeterminate anymore. Next, we detrend the returns by applying the London Metal Exchange Index (LME) as an indicator for the general market trend. This approach is supported by the positive correlations between the log return of the index and the log returns of the prices of every metal from our database except for indium (See Table 2).

With the method of detrended log returns, also called excess returns, we apply the approach of abnormal returns, well-known in the finance literature (Campbell et al., 1996). This approach methodically conducts the standardization by a linear regression model and by the determination of the corresponding residuals as illustrated in the following formulas:

$\log \left(\frac{\text { price }_{t}}{\text { price }_{t-1}}\right)=\alpha_{1}+\beta_{1} \log \left(\frac{\mathrm{LME}_{t}}{\mathrm{LME}_{t-1}}\right)+\varepsilon_{t}$

excess return ${ }_{t}=\log \left(\frac{\text { price }_{t}}{\text { price }_{t-1}}\right)-\alpha_{1}-\beta_{1} \log \left(\frac{\mathrm{LME}_{t}}{\mathrm{LME}_{t-1}}\right)$

In order to validate our theoretical results in a sound methodological manner, the excess returns have to be stationary. Otherwise, the measured return relationships may be spurious. Indeed, the results of an augmented Dickey-Fuller test reveal that the approach of abnormal returns leads to a completely stationary data base as depicted in Table 3.

The stationarity of the excess returns, further confirmed by a Leybourne-McCabe test, allows us to analyze the return relationships between primary products and their by-products with a linear regression model. Thereby, we use the excess returns of the primary product as the independent variable and the excess returns of the by-product as the dependent variable. The application of a Newey-West estimator for the error term enables us to

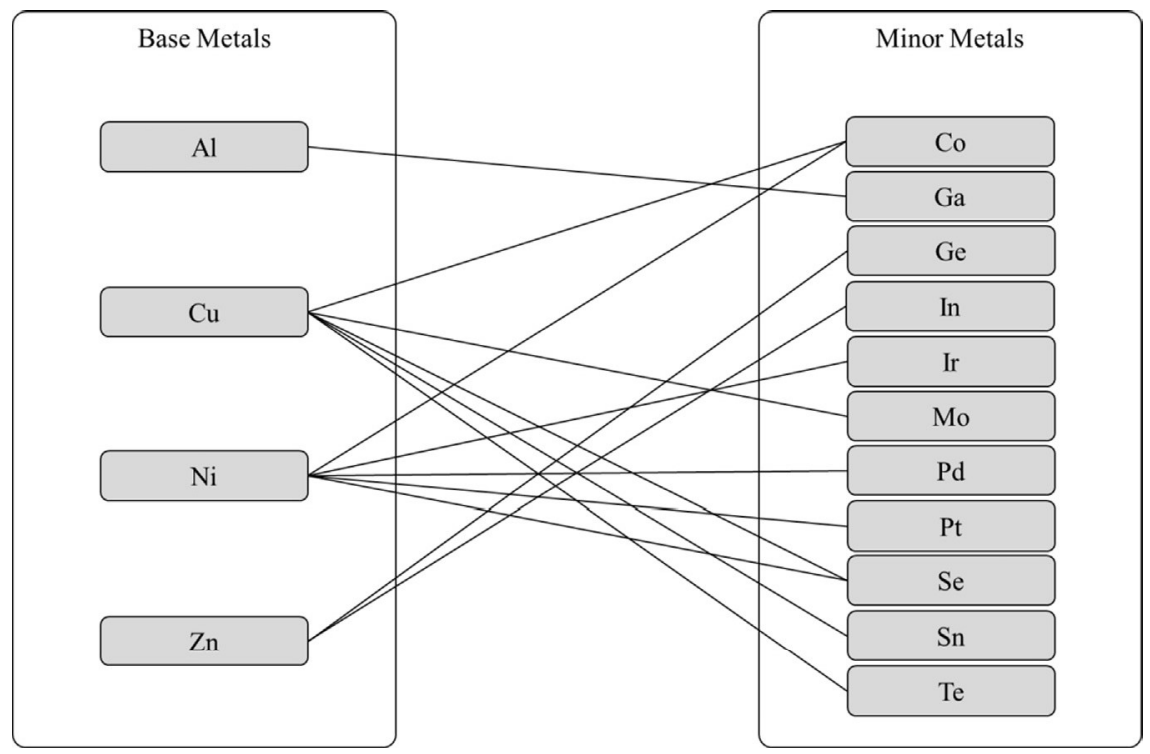

Fig. 5. Analyzed metal pairs.

Table 2

Pearson correlation between LME and metals (2009-2013) (* represents a significance level of $10 \%$, ** a significance level of $5 \%$ and $* * *$ a significance level of $1 \%$ ).

\begin{tabular}{cccccccccccccccccccc}
\hline & AL & CU & NI & ZN & SN & CO & MO & GA & GE & IN & SE & TE & IR & PD & PT & 0.18 \\
\hline LME & $0.86^{* * *}$ & $0.96^{* * *}$ & $0.86^{* * *}$ & $0.88^{* * *}$ & $0.87^{* * *}$ & $0.42^{* * *}$ & $0.30^{* *}$ & 0.18 & 0.22 & -0.05 & 0.08 & 0.02 & 0.12 & $0.79^{* * *}$ & $0.74^{* * *}$ \\
\hline
\end{tabular}

Table 3

t-statistic (Dickey-Fuller table) of the AR(1)-coefficient (excess returns 2009-2013).

\begin{tabular}{llllllllllllllllll}
\hline & AL & CU & NI & ZN & CO & SN & MO & GA & GE & IN & SE & TE & IR & PD & PT & \\
\hline Test statistic & -5.8 & -5.5 & -5.6 & -4.9 & -7.7 & -4.8 & -4.6 & -2.7 & -2.8 & -3.4 & -3.1 & -3.0 & -3.6 & -5.1 & -5.5 & \\
$p$-Value & $>0.01$ & $>0.01$ & $>0.01$ & $>0.01$ & $>0.01$ & $>0.01$ & $>0.01$ & $>0.01$ & $>0.01$ & $>0.01$ & $>0.01$ & $>0.01$ & $>0.01$ & $>0.01$ & $>0.01$ \\
\hline
\end{tabular}


overcome potential problems of autocorrelation and heteroscedasticity.

excess return $_{t}$ (by - product $)=\alpha_{2}+\beta_{2}$ excess return $_{t}$

(primary product $)_{t}+\varepsilon_{t}$

\section{Relationships of base metals and minor metals}

In order to validate our optimization model, we compare the empirical results to our theoretical prediction of negative relationships between the excess returns (See Hypothesis 1). Out of 13 test combinations, nine metal pairs (69\%) show the forecasted negative relationship whereas the regression of the other four pairs $(31 \%)$ show a positive relationship. Only the relationships zinc/germanium and copper/tin are highly significant (one-percent significance level). However the excess returns of both metal pairs negatively depend on each other and support our theoretical findings. The metal pairs which show a significant return relationship (10-percent significance level) paint a mixed picture: the relationships nickel/cobalt is negative and the relationship aluminum/gallium is positive. A possible explanation for the positive dependency between aluminum and gallium may be that the demand for gallium is below its maximum production capacity from the bauxite refinement within the aluminum production process (USGS, 2013). This means that the gallium price equals its separate optimum, which leads to a decoupling of the prices as illustrated in the theoretical framework. Overall, our empirical analysis cannot finally prove the existence of a by-product effect as only three metal combinations significantly illustrate the forecasted negative relationship. However, there are also aspects within our analysis that strongly imply the validity of our optimization model. First, the only misclassification among the significant relationship can be explained by our theoretical findings in combination with the analysis of the general market framework and the production conditions for aluminum and gallium. Second, the empirical relationships of the combinations of by-products and primary products, clearly tends to be negative. Table 4 describes the outcomes of the linear regressions.

Robustness check

In this section, we validate the robustness of our empirical results. Therefore, we apply our methodology to every possible combination between a base metal and a minor metal that are not produced jointly in the real world. The analysis shows that the directions of the relationships are equally distributed over the 31 test combinations. This observation holds for the overall data set as well as for the significant and the highly significant return relationships. The results from the test-combination thereby suggest that the signs of the relationships are random, and that no pattern becomes apparent through analyzing the data. It further illustrates that the results for the existing by-products are not spurious and do not originate from a biased methodology. Furthermore, our identified results propose that the theoretically described by-product effect could exists for minor metals and their base metals with a relatively high degree of certainty. Table 5 describes the results of our robustness check.

\section{Conclusion and future research}

Campbell (1985), Naumov and Grinberg (2009), Kim and Heo (2012) and Fizaine (2013) analyze price dependencies between metallic primary products and by-products. Campbell (1985) illustrates that the mining of primary products and co-products has a stabilizing effect on the mining industry. He further states
Table 4

Estimate of eq. (23) (pairs according to Fig. 5, 2009-2013: column 3-6: beta, standard error, $t$-value, and $p$-Value of beta, * represents a significance level of $10 \%$, ** a significance level of $5 \%$ and $* * *$ a significance level of $1 \%$ ).

\begin{tabular}{llllrl}
\hline By-product & Primary product & Estimate & Std. error & $\boldsymbol{t}$-Value & $\boldsymbol{p}$-Value \\
\hline CO & CU & -0.318 & 0.300 & -1.061 & 0.149 \\
CO & NI & $-0.187^{*}$ & 0.135 & -1.386 & 0.088 \\
GA & AL & $1.008^{*}$ & 0.672 & 1.502 & 0.072 \\
GE & ZN & $-0.825^{* * *}$ & 0.268 & -3.078 & 0.002 \\
IN & ZN & -0.099 & 0.288 & -0.344 & 0.367 \\
IR & NI & 0.305 & 0.289 & 1.057 & 0.150 \\
MO & CU & 0.089 & 0.431 & 0.206 & 0.419 \\
PD & NI & -0.082 & 0.137 & -0.601 & 0.276 \\
PT & NI & -0.199 & 0.235 & -0.847 & 0.202 \\
SE & CU & -0.849 & 1.238 & -0.686 & 0.249 \\
SE & NI & 0.166 & 0.391 & 0.425 & 0.337 \\
SN & CU & $-1.757^{* * * *}$ & 0.431 & -4.077 & 0.000 \\
TE & CU & -0.708 & 1.395 & -0.507 & 0.308 \\
\hline
\end{tabular}

Table 5

Estimate of equation (25) (random pairs, 2009-2013): column 3-6: beta, standard error of beta, $t$-value, and $p$-Value of beta, * represents a significance level of $10 \%$, ** a significance level of $5 \%$ and *** a significance level of $1 \%$ ).

\begin{tabular}{|c|c|c|c|c|c|}
\hline By-product & Primary product & Estimate & Std. error & $t$-Value & p-Value \\
\hline $\mathrm{CO}$ & $\mathrm{AL}$ & $0.031^{* * * *}$ & 0.261 & 0.118 & 0.453 \\
\hline $\mathrm{CO}$ & $\mathrm{ZN}$ & -0.057 & 0.184 & -0.311 & 0.379 \\
\hline GA & $\mathrm{CU}$ & -0.796 & 0.764 & -1.042 & 0.153 \\
\hline GA & NI & -0.341 & 0.340 & -1.002 & 0.163 \\
\hline GA & $\mathrm{ZN}$ & -0.312 & 0.338 & -0.923 & 0.182 \\
\hline GE & $\mathrm{AL}$ & 0.322 & 0.290 & 1.110 & 0.138 \\
\hline GE & $\mathrm{CU}$ & -0.297 & 0.698 & -0.425 & 0.337 \\
\hline GE & $\mathrm{NI}$ & $0.399 *$ & 0.292 & 1.366 & 0.092 \\
\hline IN & $\mathrm{AL}$ & $1.106^{* * * *}$ & 0.498 & 2.219 & 0.018 \\
\hline IN & $\mathrm{CU}$ & -0.727 & 0.635 & -1.144 & 0.131 \\
\hline IN & NI & $-0.441^{*}$ & 0.264 & -1.669 & 0.053 \\
\hline IR & $\mathrm{AL}$ & 0.132 & 0.164 & 0.804 & 0.214 \\
\hline IR & $\mathrm{CU}$ & -0.559 & 0.637 & -0.877 & 0.194 \\
\hline IR & $\mathrm{ZN}$ & $-0.132^{* *}$ & 0.076 & -1.730 & 0.047 \\
\hline MO & $\mathrm{AL}$ & -0.125 & 0.365 & -0.344 & 0.367 \\
\hline MO & $\mathrm{NI}$ & 0.050 & 0.168 & 0.299 & 0.384 \\
\hline MO & $\mathrm{ZN}$ & -0.042 & 0.233 & -0.183 & 0.428 \\
\hline PD & $\mathrm{AL}$ & -0.230 & 0.242 & -0.950 & 0.175 \\
\hline PD & $\mathrm{CU}$ & $0.885^{*}$ & 0.550 & 1.610 & 0.059 \\
\hline PD & $\mathrm{ZN}$ & -0.361 & 0.279 & -1.292 & 0.104 \\
\hline PT & $\mathrm{AL}$ & 0.186 & 0.190 & 0.976 & 0.169 \\
\hline PT & $\mathrm{CU}$ & 0.057 & 0.286 & 0.200 & 0.422 \\
\hline PT & $\mathrm{ZN}$ & -0.135 & 0.173 & -0.780 & 0.221 \\
\hline SE & $\mathrm{AL}$ & 0.828 & 0.758 & 1.092 & 0.142 \\
\hline SE & $\mathrm{ZN}$ & $-0.969^{* *}$ & 0.489 & -1.982 & 0.029 \\
\hline SN & $\mathrm{AL}$ & $0.660 * * *$ & 0.273 & 2.418 & 0.011 \\
\hline SN & NI & $0.485^{* *}$ & 0.281 & 1.726 & 0.048 \\
\hline SN & $\mathrm{ZN}$ & -0.121 & 0.255 & -0.476 & 0.319 \\
\hline $\mathrm{TE}$ & $\mathrm{AL}$ & 0.833 & 0.935 & 0.891 & 0.191 \\
\hline TE & $\mathrm{NI}$ & 0.143 & 0.372 & 0.385 & 0.352 \\
\hline $\mathrm{TE}$ & $\mathrm{ZN}$ & $-1.328^{* * *}$ & 0.517 & -2.571 & 0.008 \\
\hline
\end{tabular}

that the prices of co-products have a negative price relationship when the demands move in opposite directions, and that the effect is indeterminate if the demands move in the same direction (equal price drivers).

To expand economic research in this field, we develop an optimization model that examines the price dependencies of primary products and their by-products in the mining industry. This enables us to get more detailed insights into the price dependencies and their conditions. In this paper, we illustrate that the prices of primary products and their by-products shift in opposite directions in the case of a demand shock. This result is in 
line with the findings of our literature research. Our optimization model further reveals that equal price drivers and decoupling are market situations in which the by-product effect vanishes. The condition of equal price drivers is especially common in today's mining industry (Chen et al., 2010). Our model suggests that the previous research results about the by-product effect can therefore not directly be transferred to today's markets for minor metals. In contrast to Campbell (1985) and Fizaine (2013), minor metals and their base metals do not develop independently in their present markets. This means according to our optimization model that the negative price relationship from the by-product effect has to be translated into a negative relationship between deviations from the general market trend. If a base metal outperforms the general market trend, the prices for the associated minor metals realize in a level below the market trend. If a base metal underperforms the general market trend, the price for the associated minor metal realizes in a level above the market trend.

A second contribution to economic research, delivered in this paper, is the empirical application of our model to the markets of minor metals. These metals are of growing importance in today's industry, which makes the analysis of their price dynamics increasingly relevant. Given our theoretical results on the effects of equal price drivers, we expand existing empirical approaches by additionally detrending the prices with a general market trend (LME). The empirical analysis indicates that our derived byproduct effect exists for minor metals and the corresponding base metal.

There are still some aspects that call for future research. For example, a very common condition in the real world is that some by-products are extracted with more than one primary product, (e.g. cobalt with nickel and cooper) or that some primary products are also by-products of other metals. Thus, our model could be extended to reflect these complex production dependencies. Another area, in which future research is grounded, results from the fact that still more and more metals are used in industrial products and therefore, might be traded at exchange markets. Consequentially, there will be longer time series and even more metal combinations in the future that could be used to challenge our approach. Indeed, we consider our short time series as the main reason for the small number of empirically significant return relationships. Therefore, we proceed from the assumption that time is working for us and that future analyses can more clearly prove our findings. In addition, we differentiate in our optimization model between situations where the by-product effect exists and situations where the prices are decoupled. This differentiation is not applied in our empirical approach as the required data is not available. At this point, we suffer from the same issues as preceding researchers (Fizaine, 2013). This can be an aspect for future research when the required data about production rates and price elasticities become disposable. Another interesting idea is the combination of existing commodity price drivers with the by-product effect to better describe metal prices. However, our theoretical and empirical results are convincing, we are able to identify an additional influencer on the prices of metallic by-products and therefore, we provide a deeper understanding about the price behavior of minor metals.

\section{Acknowledgment}

We gratefully acknowledge the financial support of the European Regional Development Fund (ERDF) for the first three authors. Furthermore we want to thank Stephan Krohns, Institute for Materials Resource Management (University of Augsburg) as well as the anonymous reviewers for their helpful comments.

\section{References}

Alchian, A.A., 1950. Uncertainty, evolution, and economic theory. J. Polit. Econ. 58 (3), 211-221.

Arrow, K.J., Debreu, G., 1954. Existence of an equilibrium for a competitive economy. Econometrica 22 (3), 265-290.

Averch, H., Johnson, L., 1962. Behaviour of the firm under regulatory constraint. Am. Econ. Rev. 52 (5), 1053-1069.

Awokuse, T.O., Yang, J., 2003. The informational role of commodity prices in equationting monetary policy: a reexamination. Econ. Lett. 79 (2), 219-224.

Ayres, R.U., 1995. Thermodynamics and process analysis for future economic scenarios. Environ. Resour. Econ. 6 (3), 207-230.

Ayres, R.U., Ayres, L.W., Rade, I., 2002. The life cycle of copper, its co-products and by-products (Report for the Mining, Minerals and Sustainable Delevopment Project of the International Instutute for Environment and Development)

Bierens, H.J. Swanson, N.R., 2000. The econometric consequences of the ceteris paribus condition in economic theory. J. Econom. 95 (2), 223-253.

Blömer, F., Günther, H.O., 1998. Scheduling of a multi-product batch process in the chemical industry. Comput. Ind. 36 (3), 245-259.

Bublies, T., Allen, M., Meißner, S., Oswald, I., Reller, A., Staudinger, T., 2009. The mobile phone: powerful communicator and potential metal dissipator. GAIA 2 , 127-135.

Campbell, G.A., 1985. The role of co-products in stabilizing the metal mining industry. Resour. Policy 11 (4), 267-274

Campbell, H.F., 1980. The effect of capital intensity on the optimal rate of extraction of a mineral deposit. Can. J. Econ. 13 (2), 349-356.

Campbell, J.Y., Lo, A.W., MacKinlay, A.C., 1996. The Econometrics of Financial Markets. Princeton University Press, Princeton, NJ.

Chen, Y., Rogoff, K., Rossi, B., 2010. Can exchange rates forecast commodity prices? Q. J. Econ. 125 (3), 1145-1194.

Cournot, A., 1927. Researches into the Mathematical Principles of the Theory of Wealth. Macmillan, New York p. 1927

Crabbe, P.J., 1982. The effect of capital intensity on the optimal rate of extraction of a mineral deposit: a comment. Can. J. Econ. 15 (3), 534-541.

El-Diwani, G., El Rafei, S., Hawash, S., Khalil, A.A., 2012. Recovery of phorbol from oil of an Egyptian Jatropha. Asian J. Plant Sci. 11 (3), 117-123.

European Commission, 2010. Critical raw materials for the EU (Report of the Ad-hoc Working Group on defining critical raw materials). European Commission Enterprise and Industry Directorate, Brussels.

European Pathway to Zero Waste, 2011. Study into the feasibility of protecting and recovering critical raw materials through infrastructure development in the south east of England. European Pathway to Zero Waste Environment Agency, Banbury.

Fizaine, F., 2013. Byproduct production of minor metals: threat or opportunity for the development of clean technologies? The PV sector as an illustration. Resour. Policy 38 (3), 373-383.

Gordon, R.A., 1948. Short-period price determination in theory and practice. Am. Econ. Rev. 38 (3), 265-288.

Hagelüken, C., Meskers, C., 2010. Complex life cycles of precious and special metals. In: Graedel, T.E., van der Voet, E. (Eds.), Linkages of Sustainability. MIT Press, Cambridge, Mass, pp. 163-198.

Hotelling, H., 1931. The economics of exhaustible resources. J. Polit. Econ. 39 (2), 137-175.

Jain, A., Ghosh, S., 2013. Dynamics of global oil prices, exchange rate and precious metal prices in India. Resour. Policy 38 (1), 88-93.

Kim, H., Heo, E., 2012. Causality between main product and byproduct prices of metals used for thin-film PV cells. In: Proceedings of the 3rd IAEE Asian Conference, Kyoto, Japan.

Lewis, M., Brebner, D., Hsueh, M., Fu, X., Sieminski, A., Choi, S., Lewis, M.C., Curien, I., 2011. A User Guide to Commodities, 3rd edition Deutsche Bank, Frankfurt a. M.

Lewis, T.R., 1985. A note on mining with investment in capital: the effect of capital intensity on the optimal rate of extraction of a mineral deposit. Can. J. Econ. 18 (3), 665-667

Marx, K., 1867. Das Kapital: Kritik der politischen Ökonomie. Kröners Taschenausgaben, 2011

Merian, H.R., 1932. Die Volkswirtschaftliche Preisbildung der Kuppelprodukte. Z. Natl. 3 (4), 591-615.

Nalle, D.J., Montgomery, A., Arthur, J.L., Polasky, S., Schumaker, N.H., 2004 Modelling joint production of wildlife and timber. J. Environ. Econ. Manag. 48 (3), 997-1017.

Naumov, A.V., Grinberg, E.E., 2009. Several peculiarities in the analysis of the markets of rare and scattered metals after 2004. Russ. J. Non-Ferr. Met. 50 (1), 61-68.

Pindyck, R., 1982. Jointly produced exhaustible resources. J. Environ. Econ. Manag. 9 (4), 291-303.

Riebel, P., 1955. Die Kuppelproduktion. Westdeutscher Verlag, Köln p. 1955.

Sakai, Y., 1974. Substitution and expansion effects in production theory: the case of joint production. J. Econ. Theory 9 (3), 255-274.

Scheiby, D., 2009. Getting the best price for co-products. Brew. Distill. Int. 5 (7), $13-15$.

Smith, A., 1776. In: Campbell, R.H., Skinner, A.S., Raphael, D.D. (Eds.), An Inquiry into the Nature and Causes of the Wealth of Nations. Vol. I of the Glasgow Edition of the Works and Correspondence of Adam Smith. Oxford University Press, London. 
Steinbach, V., Wellmer, F.W., 2010. Consumption and use of non-renewable raw materials from an egonomic geology point of view. Sustainability 2 (5) 1408-1430.

Tamunaidu, P., Bhatia, S., 2007. Catalytic cracking of oil for the production of biofuels: optimization studies. Bioresour. Technol. 98 (18), 3593-3601.
Theis, T.N., 2007. Energy-Conserving Classical Computation: prospects and Challenges. IBM TJ. Watson Research Center. Link: 〈http://pitpas1.phas.ubc.ca/ varchive/asilomar/pitp_asilomar_theis.pdf (08.28.2012).

USGS, 2013. Mineral Commodity Summaries. Link: 〈http://minerals.usgs.gov/ miner als/pubs/mcs/> (04.11. 2013). 